\title{
Hemorrhagic Fever with Renal Syndrome Induced Chronic Renal Dysfunction
}

\author{
Moses S. Elisaf Kostas C. Siamopoulos \\ Department of Internal Medicine, University of loannina Medical School, loannina, Greece
}

Dear Sir,

Hemorrhagic fever with renal syndrome (HFRS) is an acute febrile nephropathy which leads to profuse albuminuria and azotemia and is caused by closely related zoonotic viruses of the genus Hantavirus of the family Bunyaviridae [1]. In this context, we read with great interest the recently published paper by Kim et al. [2] concerning the renal tubular functions during the convalescent phase of the disease. This study suggests that during this phase of the disease the urine concentrating ability is obviously impaired due to reduced collecting duct responsiveness to vasopressin [2]. Herein, we would like to present our data on the permanent renal sequelae found in HFRS patients. During the last 10 years, 32 patients with HFRS have been diagnosed in our center [3]. Seven patients died, 23 patients were discharged healthy, while in another 2 patients some degree of renal dysfunction which remained stable 12-15 months later was evident. Kid- ney biopsy in 1 of these patients with impaired renal function of a duration exceeding 12 months after discharge revealed ischemic areas with sclerosed glomeruli and mild interstitial fibrosis. In 12 out of the 23 healthy individuals, in whom examination of the renal function was performed 15 years after discharge, chronic renal dysfunction was found in $33 \%$ of them. In addition, 3 out of the 12 patients had renal tubular acidosis type I (complete in 1 and incomplete in 2 patients), and 2 patients ( 1 of whom also had incomplete renal tubular acidosis), had reduced urine concentrating ability. The development of chronic renal dysfunction was independent of the clinical severity of the acute illness [4].

We conclude that HFRS can cause chronic renal dysnfunction in a limited number of patients which seems to be independent of the clinical severity of the acute phase of the disease.

\section{References}

1 World Health Organization: Haemorrhagic fever with renal syndrome: Memorandum from a WHO meeting. Bull WHO 1983;61:269-275.

2 Kim G-H, Han JS, Earm J, Jeon US, Kim YS, Ahn C, Kim S, Lee JS: Evaluation of renal tubular functions in convalescent phase of hemorrhagic fever with renal syndrome. Am J Nephrol 1998;18:123-130.

3 Siamopoulos KS, Elisaf M, Antoniadis A, Moutsopoulos HM: Hemorrhagic fever with renal syndrome in an endemic area of Greece. Am J Nephrol 1992;12:170-173.

4 Elisaf M, Korakis H, Siamopoulos KC: Chronic renal dysfunction in hemorrhagic fever with renal syndrome patients. Ren Fail 1993; 15:623-627.

\section{KARGER \\ Fax +4161306 1234}

E-Mail karger@karger.ch www. karger.com (c) 1999 S. Karger AG, Basel

0250-8095/99/0196-0709\$17.50/0

Accessible online at: www. karger.com/journals/ajn
Moses S. Elisaf, MD

Department of Internal Medicine

University of Ioannina, Medical School

GR-451 10 Ioannina (Greece)

Tel. +30 65197509, Fax +30 65145944 